\title{
Modeling the Information-Seeking Behavior of Social Scientists: Ellis's Study Revisited
}

\author{
Lokman I. Meho \\ School of Information Science \& Policy, University at Albany, State University of New York, Draper 113, \\ 135 Western Ave., Albany, NY 12222. E-mail: meho@albany.edu \\ Helen R. Tibbo \\ School of Information \& Library Science, University of North Carolina, 201 Manning Hall, CB\# 3360, \\ Chapel Hill, NC 27599-3360. E-mail: tibbo@ils.unc.edu
}

\begin{abstract}
This paper revises David Ellis's information-seeking behavior model of social scientists, which includes six generic features: starting, chaining, browsing, differentiating, monitoring, and extracting. The paper uses social science faculty researching stateless nations as the study population. The description and analysis of the information-seeking behavior of this group of scholars is based on data collected through structured and semistructured electronic mail interviews. Sixty faculty members from 14 different countries were interviewed by e-mail. For reality check purposes, face-to-face interviews with five faculty members were also conducted. Although the study confirmed Ellis's model, it found that a fuller description of the information-seeking process of social scientists studying stateless nations should include four additional features besides those identified by Ellis. These new features are: accessing, networking, verifying, and information managing. In view of that, the study develops a new model, which, unlike Ellis's, groups all the features into four interrelated stages: searching, accessing, processing, and ending. This new model is fully described and its implications on research and practice are discussed. How and why scholars studied here are different than other academic social scientists is also discussed.
\end{abstract}

\section{Introduction}

Information-seeking behavior of academic scholars has been the focus of inquiry within the library and information science community for decades (American Psychological Association, 1963-1969; Bath University, 1979, 1980; Earle \& Vickery, 1969; Garvey \& Griffith, 1963-1967, 1971; Garvey, Lin, \& Nelson, 1970, 1971; Line, 1971,

Received June 14, 2002; revised November 8, 2002; accepted November 8, 2002

(C) 2003 Wiley Periodicals, Inc.
1973; Line, Brittain, \& Cranmer, 1971). Initially, researchers conducted user and use studies primarily for evaluating collections (Broadus, 1977a, 1977b, 1980; Christiansen, Davis, \& Reedscott, 1983; Subrahmanyam, 1983). These were followed by studies aimed at discovering useful information about the research habits of individuals or groups to design appropriate systems and services that could facilitate those habits (Belkin, Oddy, \& Brooks, 1982a, 1982b; Ellis, 1989, 1993; Kuhlthau, 1993; Marchionini, 1995).

In response to calls in the mid-1980s for more focus on the user rather than the system, this field experienced a major shift both in conceptualization and research design (Dervin \& Nilan, 1986). Most use and user studies evolved into examination of information-seeking behavior employing more holistic approaches to the study of informationseeking behavior (Fidel, 1993; Pettigrew, Fidel, \& Bruce, 2001; Wang, 1999). This was characterized by a change in the nature of data collection from studying large groups via questionnaires or structured interviews, to studying small groups via observation or unstructured interviews. This was also, and perhaps more importantly, characterized by a change in the nature of the approach to analysis, in particular by the explicit attempt to generate models of the information-seeking patterns of the individuals or groups studied (Ellis \& Haugan, 1997, pp. 384-385). One of the best examples of this kind of approach to analysis can be found in the influential works of David Ellis.

Ellis $(1987,1989)$ carried out a study in which he used semi-structured interviews for data collection and Glaser and Strauss's grounded theory for data analysis. His research resulted in a pattern of information-seeking behavior among social scientists that included six generic features:

- Starting: comprising those activities characteristic of the initial search for information such as identifying references that could serve as starting points of the research cycle. These 
references often include sources that have been used before as well as sources that are expected to provide relevant information. Asking colleagues or consulting literature reviews, online catalogs, and indexes and abstracts often initiate starting activities.

- Chaining: following chains of citations or other forms of referential connection between materials or sources identified during "starting" activities. Chaining can be backward or forward. Backward chaining takes place when references from an initial source are followed. In the reverse direction, forward chaining identifies, and follows up on, other sources that refer to an original source.

- Browsing: casually looking for information in areas of potential interest. It not only includes scanning of published journals and tables of contents but also of references and abstracts of printouts from retrospective literature searches.

- Differentiating: using known differences (e.g., author and journal hierarchies or nature and quality of information) between sources as a way of filtering the amount of information obtained.

- Monitoring: keeping abreast of developments in an area by regularly following particular sources (e.g., core journals, newspapers, conferences, magazines, books, and catalogs).

- Extracting: activities associated with going through a particular source or sources and selectively identifying relevant material from those sources (e.g., sets of journals, series of monographs, collections of indexes, abstracts or bibliographies, and computer databases).

Significant on its own, the importance of Ellis's model is enhanced by the fact that it has strong similarities with other influential models, such as that of Kuhlthau (1988, 1991, 1993), particularly in terms of the various types of activities or tasks carried out within the overall information-seeking process (Wilson, 1999). Ellis's model is also important because it was based on empirical research and has been used in many subsequent studies and with various groups of users (Bates, 1989; Choo, Detlor, \& Turnbull, 1998, 2000; Ellis \& Haugan, 1997; Sutton, 1994). Ellis's categorization of actual information-seeking behavior activities among social scientists suggested that information retrieval systems could increase their usefulness by including features that directly support these activities. Certainly, most of the information-seeking behavior features in Ellis' model are now being supported by capabilities available in Web browsers. For example, an individual could begin surfing the Web from one of a few favorite pages or sites (starting); follow links to related information resources - in both backward and forward linking directions (chaining); scan the web sites of the sources selected (browsing); bookmark useful sources for future reference (differentiating); subscribe to e-mail based services that alert the user of new information or developments (monitoring); and search a particular source or site for all information on that site on a particular topic (extracting) (Choo, Detlor, \& Turnbull, 2000).

As of 2002, there were more than 150 papers that cite Ellis's information-seeking behavioral model of social sci- entists (Institute for Scientific Information, 2002). Despite this, no attempt has been made to replicate his study. In fact, with the exception of Ellis's work, studies investigating academic social scientists have been in steady decline since the mid-1970s (Hobohm, 1999). According to Line (2000), in an information world radically changed by the Internet, it is judged as being essential to carry out new studies into information uses and needs. It is therefore the intent of this article to update the work done by Ellis. An update is important particularly because Ellis's study on social scientists was conducted prior to the development of the World Wide Web (WWW) and also because his conclusions were based on a sample of researchers from a single university in the United Kingdom. Thus, it is important to know if there are new information-seeking activities that are being brought about by changes in information technology and if so, what these activities are, what we can conclude from them, and what implications they hold for the enhanced design of information services and systems.

This study describes and analyzes the information-seeking behavior of social science faculty studying stateless nations. A main reason for choosing this population is because these scholars have never been investigated before as a separate group of users. More importantly, however, these scholars were chosen because of their diversity in terms of research areas, sub-disciplines, countries of origin, and linguistic skills.

A social science faculty member in this study refers to any scholar who is a member of one, or a combination of two or more, of the following academic sub-disciplines: anthropology, area studies, communication, economics, education, geography, history, political science, psychology, public administration, sociology, and women's studies. A social science faculty member is also any person who considers him or herself so, provided that he or she is a member of an academic department.

Like "social science faculty member," the term stateless nations or nations without states is defined very broadly: those regionally concentrated peoples that have lost their autonomy before and after World War I but still preserve their cultural distinctiveness and want to re-establish a politically separate existence. The sources used to discover these stateless nations were:

- James Minahan (1996), who provides detailed information on 210 major nations without states and asserts that these "represent only a fraction of the world's stateless nations;" and

- Ted Robert Gurr (2000), who identifies 275 main minority

\footnotetext{
${ }^{1}$ Factors that influenced his selection criteria included: (1) A national claim to a recognizable geographic area; (2) The display of outward trappings of national consciousness, particularly the adoption of a flag, a very important and very emotional part of any nationalism; and (3) The formation of a specifically nationalist organization that reflects the nation's claim to self-determination.
} 
TABLE 1. Stateless nations identified in the study $(n=32)$.

\begin{tabular}{|c|c|}
\hline Stateless nation & Country \\
\hline \multicolumn{2}{|c|}{ Western democracies } \\
\hline Natives & Canada \\
\hline Quebecois & Canada \\
\hline Corsicans & France \\
\hline Sardinians & Italy \\
\hline Basques & Spain \\
\hline Catholics in Northern Ireland & UK \\
\hline Scots & UK \\
\hline \multicolumn{2}{|c|}{ Eastern Europe/former Soviet Union } \\
\hline Abkhazians & Georgia \\
\hline Ajarian/Adzhars & Georgia \\
\hline Ossetians (South) & Georgia \\
\hline Chechens & Russia \\
\hline Dagestanis & Russia \\
\hline Tatars & Russia \\
\hline Crimean Tatars & Ukraine \\
\hline \multicolumn{2}{|c|}{ Asia } \\
\hline Kachins & Burma \\
\hline Karens & Burma \\
\hline Shans & Burma \\
\hline Tibetans & China \\
\hline Kashmiris & India \\
\hline Sikhs & India \\
\hline Acehnese & Indonesia \\
\hline Bougainvillians & Papua New Guinea \\
\hline Moros & Philippines \\
\hline Tamils & Sri Lanka \\
\hline \multicolumn{2}{|c|}{ North Africa and the Middle East } \\
\hline Kurds & $\begin{array}{l}\text { Iran, Iraq, Syria, } \\
\text { Turkey }\end{array}$ \\
\hline Sahrawis & Morocco \\
\hline \multicolumn{2}{|c|}{ Sub-Saharan Africa } \\
\hline Afars & Eritrea \\
\hline Oromo & Ethiopia \\
\hline Tuareg & Niger \\
\hline Diolas & Senegal \\
\hline Southerners & Sudan \\
\hline Buganda & Uganda \\
\hline
\end{tabular}

Sources: Gurr (2000) and Minahan (1996).

peoples that, in 1998 , made up $17.4 \%$ of the world's population. $^{2}$

More restrictively, the stateless nations included in this study must also have supported political movements for autonomy at some time since the end of World War II (Gurr, 2000). Based on these characterizations, 32 stateless nations were identified (see Table 1). Of these 32, seven are located in "democratic" countries, namely, Canada, France, Italy, Spain, and the United Kingdom. The remaining stateless nations are located in different Asian and African countries, mostly ruled by "oppressive regimes," such as Iran, Iraq, and Turkey (see Table 1).

\footnotetext{
${ }^{2}$ Gurr's two general criteria for inclusion were: (1) The group collectively suffers, or benefits from, systematic discriminatory treatment visà-vis other groups in a society; and (2) The group is the basis for political mobilization and collective action in defense or promotion of its selfdefined interests.
}

Oppressive regimes is used here to refer to those governments that deny their subjects, particularly members of minority groups, their freedom of expression, speech, and assembly; freedom to form political parties and to run for office; participation in the decisions that shape their lives; and so on. They are governments or countries that brutally crush dissident movements and crackdown on rebellions and use extreme force to punish those groups of people that support such movements and rebellions. Primary sources are used here to refer to:

- Diaries, speeches, interviews, letters, memos, manuscripts, and other papers in which individuals describe events in which they were participants or observers.

- Memoirs and autobiographies.

- Records of or information collected by government agencies (e.g., census data).

- Records of organizations (e.g., minutes, reports, and proceedings of party meetings).

- Published materials (books, magazine and journal articles, newspaper articles) written at the time about a particular event.

- Photographs, audio recordings, and video recordings, documenting what happened.

- Materials that document the attitudes and popular thought of a historical time period.

- Research data such as anthropological field notes, the results of scientific experiments, and other scholarly activity of the time.

- Artifacts of all kinds (Library, 2002).

Secondary sources are works that interpret or analyze historical events or phenomena. They are generally at least one step removed from the event (Library, 2002). A recent article that evaluates and analyzes the relationship between searching skills and successful information retrieval is an example of a secondary source. Textbooks and encyclopedias are other examples of secondary sources.

\section{Methodology 3}

\subsection{Data Collection Tool}

The description and analysis of the information-seeking behavior of social science faculty in this study is based on data collected through structured and semi-structured electronic mail (e-mail) interviews (Curasi, 2001; Murray, 1995, 1996; Murray \& Sixsmith, 1998). The use of e-mail interviews as opposed to face-to-face interviews and/or observation was driven by the fact that very few of the potential participants were within practical geographical distance and, therefore, the latter two methods were deemed impractical. E-mail interviews were considered rather than telephone interviews because:

\footnotetext{
${ }^{3}$ For more details on the methodology, see Meho (2001).
} 
- E-mail interviews are unobtrusive and can be friendlier to participants than telephone interviews. The former also allows the participants to take their time in answering questions without the interruption of the interviewer;

- E-mail interviews are more economic in terms of time; they allow interviews with several participants to take place at once, whereas the telephone is normally used to interview one person at a time;

- E-mail interviews reduce the problem of interviewer effect in terms of, for example, personal communication skills. Through e-mail, only written correspondences are made;

- E-mail messages allow for the totality of the exchange to be reviewed by either party (interviewer and interviewee) and eliminate any errors introduced through incorrect transcription; and

- E-mail interviewing provides "ready-transcribed" data-the text from e-mail interviews can easily be tailored for word processing or computer-based qualitative analysis package with a minimum of alteration.

Despite these advantages, and despite the fact that the use of e-mail for interviewing purposes provided an opportunity to interview a much larger and more diversified group of people than was possible with traditional types of interviews, e-mail interviewing has a number of disadvantages that were taken into consideration, including:

- In e-mail interviewing, there is no direct probing. Probing can be done only in follow-up e-mails;

- In e-mail interviewing, it is not possible to listen for voice tones;

- Non-responses to questions might be more frequent in e-mail interviews than face-to-face (FTF) or telephone;

- In e-mail interviews, there is a great possibility of response delays; it may take days or even weeks before a participant answers an e-mail message; and

- The possibilities of miscommunication and misinterpretation could be higher in e-mail interviewing than in FTF or telephone interviewing.

\subsection{Selection of Participants}

The pool of social science faculty that was invited to participate in the study was identified through searching four bibliographic databases: Arts \& Humanities Citation Index, Geobase, Social Sciences Citation Index, and Sociological Abstracts. These databases were chosen primarily because they are: (1) International in character, indexing materials from more than 50 countries; (2) Comprehensive in their coverage, indexing books and over 11,000 periodicals; and (3) Multidisciplinary, covering all social sciences subdisciplines (e.g., anthropology, economics, education, ethnic studies, geography, history, political science, sociology, and women's studies, among others). The four databases were also chosen because they include a corporate source field for their records. The existence of a corporate source field was important because it made it practical to locate and identify the contact information of potential study participants. A free-text search in all four databases
TABLE 2. Distribution of faculty by country $(n=212)$.

\begin{tabular}{lclc}
\hline \multicolumn{1}{c}{ Country } & $\begin{array}{c}\text { Number of } \\
\text { scholars }\end{array}$ & \multicolumn{1}{c}{ Country } & $\begin{array}{c}\text { Number of } \\
\text { scholars }\end{array}$ \\
\hline USA & $84(39.6 \%)$ & Bangladesh & $1(0.5 \%)$ \\
UK & $40(18.9 \%)$ & Czech Republic & $1(0.5 \%)$ \\
Canada & $25(11.8 \%)$ & Finland & $1(0.5 \%)$ \\
Germany & $9(4.2 \%)$ & Hungary & $1(0.5 \%)$ \\
Turkey & $8(3.8 \%)$ & Israel & $1(0.5 \%)$ \\
Australia & $6(2.8 \%)$ & Italy & $1(0.5 \%)$ \\
India & $6(2.8 \%)$ & Japan & $1(0.5 \%)$ \\
Spain & $6(2.8 \%)$ & New Zealand & $1(0.5 \%)$ \\
Russia & $5(2.4 \%)$ & Norway & $1(0.5 \%)$ \\
Sweden & $4(1.9 \%)$ & Sri Lanka & $1(0.5 \%)$ \\
Netherlands & $3(1.4 \%)$ & Switzerland & $1(0.5 \%)$ \\
Ireland, Republic of & $2(0.9 \%)$ & Trinidad & $1(0.5 \%)$ \\
France & $1(0.5 \%)$ & Uganda & $1(0.5 \%)$ \\
\hline
\end{tabular}

was conducted on the 32 stateless nations identified in this study. The searches, which used the names and all possible name-variations of the 32 stateless nations, resulted in 31,698 records. The searches were then limited to social science (e.g., Anthropology, Ethnic Studies, History) items (articles, chapters in books, and conference papers) published in English between 1998 and 2000. The searches were limited to 1998-2000 to ensure that the information needs and seeking behavior of active researchers was examined.

After limiting the searches by language, publication date, and subject, and after removing duplicate records, the four searches resulted in 1,034 records. All records, most of which contained full bibliographic information and abstracts, were read and the relevant ones were selected. Relevance in this case was based on three criteria: (1) Topic of the item: no limitations were set to the subject matter of the records as long as the focus was on studying the stateless nations; (2) Existence of a corporate source field for each record in order to locate the e-mail addresses of the potential participants; and (3) Professional affiliation of the authors: only academic scholars were included in this study. All in all, 251 articles were found relevant. These articles were written by 212 different authors, constituting the pool of potential participants for the study. Most of these authors $(88 \%)$ were located in countries known as "Western democracies" (see Table 2). The 212 authors represented all 32 stateless nations identified in this study. Table 3 shows the breakdown of potential participants by research topic.

Since it was planned to employ electronic mail (e-mail) interviewing for collecting data from the study participants, the next step was to locate the e-mail addresses of the 212 potential participants. This was done through the Web. Each of the 212 potential participant's institutional home pages was visited and searched to locate the needed information. In the end, the location and e-mail addresses of 147 potential participants were found. The addresses of the remaining 65 potential participants were not found probably because some were graduate students who completed their degrees or faculty members who moved somewhere else. Of the 147 
TABLE 3. Distribution of faculty by research topic $(n=212)$.

\begin{tabular}{lclc}
\hline \multicolumn{1}{c}{ Research topic } & Number of scholars & Research topic & Number of scholars \\
\hline Quebecois & $25(11.8 \%)$ & Moros & $3(1.4 \%)$ \\
Kurds & $23(10.8 \%)$ & Diolas & $2(0.9 \%)$ \\
Kashmiris & $19(9.0 \%)$ & Southern Sudanese & $2(0.9 \%)$ \\
Basques & $16(7.5 \%)$ & Tuareg & $2(0.9 \%)$ \\
Chechens & $16(7.5 \%)$ & Abkhazians & $1(0.5 \%)$ \\
Catholics in Northern Ireland & $14(6.6 \%)$ & Acehnese & $1(0.5 \%)$ \\
Tamils & $14(6.6 \%)$ & Adzhars/Ajarian & $1(0.5 \%)$ \\
Tibetans & $12(5.7 \%)$ & Afars & $1(0.5 \%)$ \\
Miscellaneous* & $9(4.2 \%)$ & Corsicans & $1(0.5 \%)$ \\
Crimean Tatars & $7(3.3 \%)$ & Daghestanis & $1(0.5 \%)$ \\
Oromo & $7(3.3 \%)$ & Kachins & $1(0.5 \%)$ \\
Tatars & $7(3.3 \%)$ & Karens & $1(0.5 \%)$ \\
Natives in Canada & $6(2.8 \%)$ & Ossetians & $1(0.5 \%)$ \\
Sikhs & $5(2.4 \%)$ & Sardinians & $1(0.5 \%)$ \\
Buganda & $4(1.9 \%)$ & Scots & $1(0.5 \%)$ \\
Sahrawis & $4(1.9 \%)$ & Shans & $1(0.5 \%)$ \\
Bougainvilleans & $3(1.4 \%)$ & & \\
\hline
\end{tabular}

* Faculty members included in this category are those who study two or more stateless nations.

addresses that were found, eight were for graduate students and were thus removed from the list, making the final number of potential participants 139 . Of these 139 potential participants, nine were located within practical geographical distance. These were reserved for FTF interviews, which were conducted for reality-check purposes. The remaining 130 potential participants were sent invitations to participate in the e-mail interview.

Of these 130, nine indicated that they do not conduct research on "stateless nations," 4 two indicated that they are not working on the topic anymore, one did not consider himself a social scientist, and 12 did not have working e-mail addresses. Of the remaining 106 potential participants, 16 declined for lack of time and 30 did not respond. The final number of faculty who participated in e-mail interviewing, which took place in December 2000-April 2001, was 60 (or 56.6\%). Those demographics, which can be reported without violating assurances of confidentiality, are included in Tables 4-6.

The primary limitation of this study regarding the selection of participants is that the sample necessarily omitted

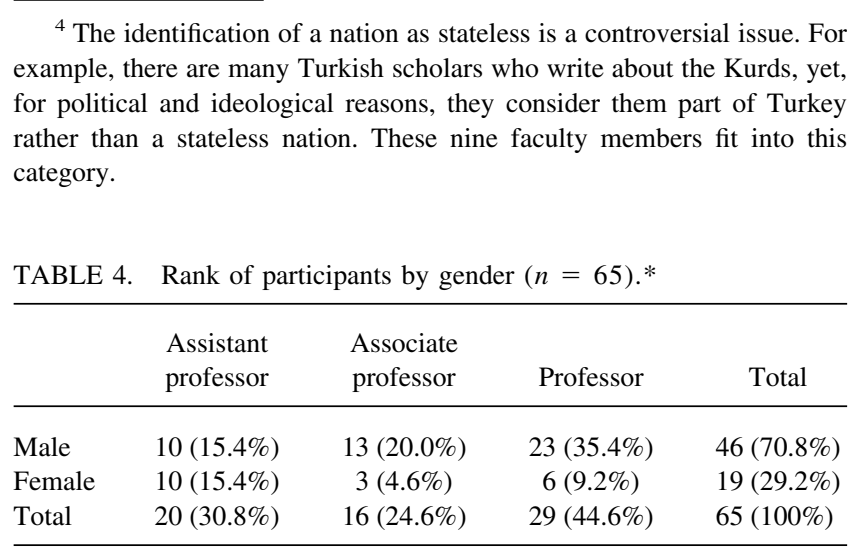

* Includes FTF participants. faculty who do not publish in English. Moreover, the use of Arts \& Humanities Citation Index, Geobase, Social Sciences Citation Index, and Sociological Abstracts meant that faculty who do not publish in periodicals that are indexed in these databases would not be included in the sample. Despite these limitations, this work examined a large and diverse sample of the population. The study also generated enough data to verify Ellis's model and produce additional features to the model.

\subsection{Interview Questions}

To make sure that key topics were explored with all e-mail study participants, a list of primary questions was developed to direct the interviewing process. The list of

TABLE 5. Discipline of participants.*

\begin{tabular}{lcc}
\hline \multicolumn{1}{c}{ Discipline } & $\begin{array}{c}\text { Number of } \\
\text { participants }\end{array}$ & $\begin{array}{c}\text { Number of } \\
\text { non-participants }\end{array}$ \\
\hline Political Science & $22(33.8 \%)$ & $25(50.0 \%)$ \\
Sociology & $12(18.5 \%)$ & $8(16.0 \%)$ \\
Anthropology & $9(13.8 \%)$ & $10(20.0 \%)$ \\
History & $6(9.2 \%)$ & $5(10.0 \%)$ \\
Geography & $4(6.2 \%)$ & $1(2.0 \%)$ \\
Area Studies & $2(3.0 \%)$ & - \\
Religious Studies & $2(3.0 \%)$ & - \\
Development Studies & $2(3.0 \%)$ & - \\
Communication & $1(1.5 \%)$ & - \\
Education & $1(1.5 \%)$ & - \\
Economics & $1(1.5 \%)$ & - \\
Health Ecology & $1(1.5 \%)$ & - \\
International Law & $1(1.5 \%)$ & - \\
Oriental Cultures & $1(1.5 \%)$ & $50(100.0 \%)$ \\
Sports Studies & $1(1.5 \%)$ & \\
Total & $65(100.0 \%)$ & \\
\hline \multicolumn{1}{c}{$*$ Includes FTF participants. } & &
\end{tabular}


TABLE 6. Geographical location of participants.*

\begin{tabular}{lcc}
\hline \multicolumn{1}{c}{ Location } & $\begin{array}{c}\text { Number of } \\
\text { participants }\end{array}$ & $\begin{array}{c}\text { Number of } \\
\text { non-participants }\end{array}$ \\
\hline United States & $31(47.7 \%)$ & $26(52.0 \%)$ \\
United Kingdom & $10(15.4 \%)$ & $8(16.0 \%)$ \\
Canada & $7(10.8 \%)$ & $7(14.0 \%)$ \\
Australia & $3(4.6 \%)$ & $2(4.0 \%)$ \\
Netherlands & $3(4.6 \%)$ & - \\
Sweden & $3(4.6 \%)$ & $1(2.0 \%)$ \\
Germany & $2(3.1 \%)$ & - \\
Turkey & $2(3.1 \%)$ & - \\
Bangladesh & $1(1.5 \%)$ & - \\
Finland & $1(1.5 \%)$ & - \\
Israel & $1(1.5 \%)$ & $1(2.0 \%)$ \\
Republic of Ireland & $1(1.5 \%)$ & $1(2.0 \%)$ \\
Italy & - & $50(100.0 \%)$ \\
Russia & - & \\
Total & $65(99.9 \%)$ & - \\
\hline
\end{tabular}

* Includes FTF participants.

questions-initially composed of 22 open-ended questions - was revised and expanded as more e-mail interviews were conducted. The final version of the list included 25 open-ended questions that covered the demographics of the participants and their research topics; their information use patterns; their methods of locating information and the problems they encounter in the process; their methods of keeping up-to-date with developments in their research field and the problems they face in this respect; and their helpseeking behavior and use of information technology.

Probing, in the form of follow-up questions, was attempted with all participants. An example of a probing incident is: "You mentioned that you follow-up references cited in materials you read. Do you use any citation databases for similar purposes (e.g., Social Sciences Citation Index)? If so, could you please describe your experience using this or another citation database?"

Of the 60 faculty members who were interviewed by e-mail, 15 participants $(25.0 \%)$ did not reply to the followup questions. There were no significant differences between these 15 participants and those who replied to the follow-up questions. To encourage the faculty to participate in the study, they were offered three incentives: (1) Two online bibliographic searches on topics of their choice utilizing relevant social science and humanities indexes and abstracts; (2) Photocopying for each one of them up to ten articles that they need for their own research; and (3) A citation search.

\subsection{Data Collection and Analysis}

Once contact information of all potential participants was collected, a test with 14 potential participants was administered to discover the best method for yielding higher participation and discussion rates. Of the 14 scholars invited, six participated. The test showed that participants prefer receiving all interview questions in one e-mail rather than in installments. As a result, data collection continued accordingly. In addition to discovering the best e-mail interviewing method, the purpose of the test was to verify the clarity of the questions and modify them based on the feedback received.

While analyzing the initial data as they were received, follow-up questions based on what was written were emailed back to the respondents. After notes were made, invitations were sent out to a new group of 14 randomly selected potential participants. As with the first group (or the test group) of potential participants, data received from those who decided to participate were subsequently analyzed and follow-up questions were immediately e-mailed back to the participants. Again, after notes were made, another group of 14 randomly selected potential participants was invited and similar data collection and analysis procedures were followed. Simultaneously, reminders to nonrespondents were sent out to the members of earlier groups, usually 1 week after the date of the initial invitation was made. These reminders consisted of all materials that were e-mailed in the first invitation and helped increase the number of participants by one-third.

After all e-mail interviews were completed and the data were given a preliminary analysis, the nine potential participants that were located within practical geographical proximity were invited to participate in FTF interviews. Five responded affirmatively. Table 7 includes the demographics of the FTF participants. All interviews took place in AprilJuly 2001 and were tape-recorded in the participants' departmental offices and lasted an average of $1 \mathrm{hr}$ each. The interviews were based on the questions used in the e-mail interviews. Although only five people were interviewed in-person, the amount of data obtained was substantial-the interviews produced 26,571 words (or 5,314 per participant).

By the end of the data collection process, all interview data, as well as the notes, were transformed into MS Word files and printed out. Using the content analysis method (Nuendorf, 2002; Roberts, 1997; West, 2001), all of the data were coded using Ellis's six information-seeking categories. The initial search for patterns and themes was not intended to produce or confirm a final list of categories, but was meant to begin the process of their development and to understand the issues mentioned by the participants. After the first coding attempt was completed, a new coding process began again.

TABLE 7. Demographics of FTF interviewees $(n=5)$.

\begin{tabular}{llll}
\hline Name & Gender & Rank & \multicolumn{1}{c}{ Discipline } \\
\hline 61 & Male & Associate & Sociology \\
62 & Male & Assistant & Anthropology \\
63 & Male & Associate & History \\
64 & Male & Professor & Sociology \\
65 & Male & Professor & Political Science \\
\hline
\end{tabular}

* Refers to the way participants describe the nature or characteristics of their research. 
Before this second and final set of codes was developed, all e-mail interview data, as well as FTF interview data, were read again twice. With each reading, additional notes that suggested categories were written on the left and right margins of the text. This new coding scheme identified all the categories and their indicators discussed in this study. An example of a category and its indicator is the incident "I browse tables of contents," which was listed under the category "browsing."

Once all coding was complete, coding check was used to insure consistency in the application of the codes. A random sample of data was selected from each data set (i.e., e-mail interview data and FTF interview data) and given to two library and information science doctoral students. These students were asked to re-code the two samples based on the final list of codes developed by the investigators. If the level of agreement between the investigator and the two students was over $90 \%$, as recommended by Miles and Huberman (1984), then the coding was considered very satisfactory. If not, then all of the data would be reviewed and augmented in light of the revealed problems, after which a new sample would be chosen and the same check for consistency repeated. Re-coding for both samples came in at $93 \%$. After final coding had been completed, then the final generation of the model was begun.

The interviews produced 69,291 words of data $(42,720$ from e-mail interviews or 712 words per participant, and 26,571 from FTF interviews or 5,303 words per participant). The 65 participants interviewed were broadly diverse in terms of gender, rank, discipline, geographical location, and research topics. Nineteen participants were females and 46 were males. Twenty were assistant professors, 16 were associate professors, and 29 were professors. Forty-three participants study stateless nations ruled by "non-democratic" governments, and the remaining 22 participants study stateless nations ruled by "democratic" governments. The majority of respondents $(91 \%)$ tend to do individual research; only six respondents indicated working in teams and/or collaborating with others on research projects. Approximately three-fourths of the participants were native speakers of English and one-fourth has published in both English as well as in other languages (e.g., Dutch, French, German, and Spanish). Non-participants shared similar demographics with participants (see, for example, Tables 5 and 6).

\section{Context}

\subsection{Obstacles Faced by Scholars}

Table 1 shows that most stateless nations live under the rule of oppressive regimes (e.g., Chechens in Russia and Tibetans in China), whereas only a few enjoy some degree of democratic life under "liberal regimes" such as the Que- becois in Canada and the Scots in United Kingdom. ${ }^{5}$ According to Bozarslan (2000), Meho and Haas (2001), and data collected in this study, scholars studying stateless nations living under the rule of oppressive regimes, as opposed to those living in "Western democracies," face four major obstacles in their research process.

The first obstacle is linked to a lack of adequate academic structures and research support. In contrast to the study of Western democracies' stateless nations-where several specialized academic departments or programs are established for that purpose (e.g., Basque Studies Program at University of Nevada at Reno) - the study of developing countries' stateless nations lacks adequate academic and research support. To the best knowledge of the authors, there are no academic programs that are exclusively devoted to the study of developing countries' stateless nations. Most of the research on these groups is subsumed under the broader category of area studies programs, such as Asian and Middle Eastern studies programs, or under traditional disciplinary programs, such as History and Political Science. This lack of specialized academic programs not only reduces the chances of collaboration and interaction among scholars but also makes it difficult for librarians to develop a fuller understanding of their institutions' academic make up, which is needed to build relevant collections and design appropriate systems and services.

In addition, although lack of research funds may not be a unique characteristic of scholars studying stateless nations, the reasons for inadequate funding for these scholars may be different from the universal population of social science faculty. Several participants reported that governments and institutions do not provide them with research or grant awards because of their research topics.

The researcher on non-state nations is often perceived as cooperating with an enemy [or with] an armed opposition group or is herself/himself perceived as an enemy, not only by the respective governments, but often also by third governments, researcher[s] from the dominant ethnic group of the respective country, [and] sometimes even by international academia. This can have effects on access to jobs, funding, and other resources and can lead to a kind of isolation in the academia. At least, it often leads to fierce, emotional attacks just for having mentioned the non-state nation in a presentation. $(40)^{6}$

First, one is constantly confronted with scholars whothrough Fulbrights, consultant work, and other ties-be-

\footnotetext{
${ }^{5}$ Stateless nations in Western democracies, from a global perspective, are distinct from those in other world regions because they usually express their grievances through protest as opposed to rebellion, and the responses of their governments tend generally to accommodate their interests, not to enforce their subordination or incorporation (Ciment, 1999, p. 67).

${ }^{6}$ For confidentiality purposes, participants are referred to by numbers rather than by their actual names. Similarly, where needed, the identity of stateless nations is hidden, especially for those nations that are understudied. When quoted, the name of the nation is replaced by the phrase "stateless nation" to hide the identity of scholars studying it.
} 
come apologists for the occupying powers who accuse us of being partisans, un-objected, etc. Second, we usually can't get the Fulbrights, consultant work, etc. in the stateless nations. Third, it is quite difficult to get funding for such research outside of conflict resolution-type research or something apolitical. (47)

The lack of funds influences the participants' research in a variety of ways. It limits access to the field and archives. It also limits their ability to attend conferences, purchase books, subscribe to journals, and hire research and graduate assistants.

The second obstacle is linked to sources of information. Governments in developing countries more often than not persecute members of their stateless nations and deny them freedom of movement, opinion, and expression. For various reasons, these governments intentionally neglect to, or rarely, publish and disseminate information on stateless nations. They also prohibit scholars from access to the field and deny them access to information, particularly to materials located in national archives and governmental agencies.

Our libraries often have trouble finding the sources I request, the [Russian] government is reluctant to give information-they prefer to sell it and give access to only what they want you to know. (3)

Due to political suppression in the region, the possibilities of conducting fieldwork are very limited. (24)

Archival research is fundamental to any work that deals with topics occurring before 1960. In the case of the Kurds it is important to investigate the archives in, at least, Britain, France, and Germany, as they are open. It is impossible, of course, to do any archival research in Turkey, Syria, Iraq or Iran. (26)

Because of my contacts with [stateless nation] militants, I am now persona non grata in [country] and there is some doubt as to whether I will be readmitted to the country. On my last trip, I was detained at the airport for 18 hours before intervention by the [country] embassy made it possible for me to be admitted. (35)

In the US, I file Freedom Of Information Act requests although it doesn't help very much because agencies such as the CIA never reveal anything of importance. (55)

Even if the host governments publish, or allow the publishing of, any information about the stateless nations they persecute, the information they allow to be disseminated is either exclusively pro-state or is of minimal use. As a result, researchers studying stateless nations often rely on alternative sources of information, such as individuals (e.g., government officials and ethnic party leaders), nongovernmental organizations (e.g., Amnesty International), international governmental organizations (e.g., the United Nations and the European Union), governments of world powers (e.g., the United States), and ethnic social and political organizations (Meho \& Haas, 2001). Researchers also face the problem of scatter of information and its sources. For example, scholars studying the Kurds must not only look for information in literature exclusively on the Kurds, but also in the literatures of the countries that divide them (i.e., Iran, Iraq, Syria, and Turkey), literatures in different languages, and literatures produced or located in different countries (e.g., colonial archives of the British and Ottoman empires as well as archives of the governments of France, Germany, Italy, Russia, and the United States).

The third obstacle is linked to subject indexing. Scholars studying stateless nations continue to face problems in the areas of subject headings, index terms, and classification. For example, in the indexes of many print sources, stateless nations are not listed under their names. Rather, they are listed as sub-headings under the countries dominating them. For example, if a researcher is studying the Kurds and wants to use a particular United States or United Nations source, he or she must search under Iran, Iraq, or Turkey to find the needed information. In some cases, information about the Kurds could be listed under more obscure subject headings that many researchers may miss during the search process, such as "refugees" or "minorities."

One problem the existing Kurdish libraries are up against is that of developing a useful thesaurus of key words and a consensus on how to attribute these key words to books and documents. (6)

Stateless minorities are dealt with under many headings and in many languages. They may be filed or shelved in strange ways. E.g., books with useful historical information about Kurds in Iraq may be found in a completely different section, such as Persian Gulf. (27)

Often the nations in question are not even to be found through many conventional searches; I have to look under Morocco to find information on Western Sahara, Indonesia to find information on East Timor, etc. (47).

The fourth obstacle is linked to the difficult conditions of conducting research in the field. In fact, often scholars who are members of stateless nations and are living abroad can return to their home countries and conduct fieldwork only if they pay a very high cost that can include imprisonment and death. But even for scholars who are not members of stateless nations the working conditions are also hard. Many of them are refused a visa and almost none of them can have access to the field (e.g., villages and towns where stateless nations are located) or to information (e.g., archives). These scholars must constantly worry about compromising the security of the people interviewed or observed for academic purposes (Bozarslan, 2000).

\subsection{Types of Information Sources Used}

In addition to the aforementioned obstacles, data collected in this study showed that scholars studying stateless 
nations rely heavily on fieldwork data, and on types of information that usually are difficult to find except online or in national, special, and/or well-funded research university libraries. An example of this type of information or materials is grey literature-materials produced by governmental and non-governmental organizations, academics, business and industry, in print and electronic formats, but which are not controlled by established (sometimes meaning commercial) publishers (Carroll \& Cotter, 1997; Farace, 2000). ${ }^{7}$ Data also showed that archival materials-items produced primarily by the colonial and imperial powers of the nineteenth and twentieth centuries-are of extreme importance to most study participants. Despite the fact that only six historians participated in this study, there were as many as 43 participants (or $66 \%$ of the study population) who indicated that they have physically visited archives and used archival materials at some point in their research on stateless nations.

You cannot write history without [archival materials]; they are records left by the actors. (16)

Archives are primary sources; they include decision making by governments-decisions which are often carried out and also first-hand accounts of secret discussions and observations. (55)

Books, journal articles, and newspaper articles were also indicated as important. Overall, it was found that the type of information that participants choose to identify, locate, and use is based not only on the specific research topic, the discipline, and the level of research required to satisfy the information need, but also, and perhaps more importantly, on the identity (country of publication), accuracy, objectivity, and reliability of the information.

\subsection{Sources of Information}

Contrary to the findings of previous studies concerning the universal population of social science faculty (Buttlar \& Wynar, 1992; Hernon, 1984; McBride, 1981; Stenstrom \& McBride, 1979; Vijayakumar, 1997), this study found that scholars studying stateless nations rely more on their personal collection, fieldwork, other libraries, and archives than their own university library collection. They do so because the former provide, or are considered sources of, unique, primary information-that is, archival materials, fieldwork data, rare books, and grey literature. Attitudes towards the importance of different sources of information for scholars studying stateless nations are probably best summarized by the following quotation:

\footnotetext{
${ }^{7}$ Examples of grey literature include: dissertations, theses, scientific and technical reports, preprints, conference papers, bibliographies, datasets, newsletters, working papers, speeches, and so on (Alberani, Pietrangeli, \& Mazza, 1990; Carroll \& Cotter, 1997; Gelfand, 1997).
}

The university library is of course essential for general background, theoretical and comparative materials, where (with inter-library loan) it satisfies 90 percent of my needs. However, for the information on contemporary developments among the [stateless nation] it is almost useless. My private library and the [stateless nations] libraries are then incomparably more useful. Let me give two recent articles as examples: (a) an article on the [topic] among the [stateless nation]: fieldwork $40 \%$, own collections $30 \%$, materials and information acquired specially for this article through friends and acquaintances (including interviews by mail) $30 \%$ (b) an article on [topic] and its repercussions, with historical background: fieldwork (including recent interviews) $40 \%$, own collections $30 \%$, internet (state and national sites, newspapers, etc.) $30 \%$. (6)

\section{Findings}

Extensive reading and reviewing of the interview transcripts and notes resulted in the identification of several information-seeking activities or tasks common to the participants. These activities or tasks represented the main elements of the information-seeking behavior model that emerged in this study. Although the number of FTF interviews conducted was relatively small, the FTF data confirmed the results found through e-mail interviews. These results are outlined in the next section.

\subsection{Starting}

As in Ellis's model, the activities subsumed under this category are those characteristic of the initial search for information to obtain an overview of the literature as well as to collect primary and secondary data materials. Starting is usually initiated at the beginning of a project's life cycle to approach a new topic and is recognized as a method for planned information gathering by the scholars. Literature searches, newspaper articles, and formal and informal personal contacts (sometimes in the form of interviews) with friends, colleagues, subjects, and key figures are the primary means for starting.

Literature searches are primarily used to find out what has been published on one's research topic or to find background information on a certain topic. The scholars themselves undertake these searches and, whenever needed, they seek help from colleagues, friends, librarians, and key figures-people who the scholars believe are knowledgeable about their topic and can give advice or provide suggestions.

I usually see reference librarians. I also confer with colleagues in my discipline and related disciplines. Increasingly, also, I am seeking out local scholars and intellectuals who are writing on [stateless nation] culture. (30)

I sometimes ask friends/colleagues in the same institute, members of networks and groups to which I belong, colleagues abroad. I consult with senior academics, my supervisor, librarians, and archivists. I might ask for more general 
help (major publications/journals/libraries for a specific topic) in the initial phase. (40)

Very often, literature searches are conducted using the university's online catalog, indexing and abstracting services, or browsing. However, many of the participants (approximately one-third) start with their own personal collection first, which includes both primary and secondary sources: "By now I have a large collection of books and documents and a customized database that often is the first place to consult" (6). Data also indicated that participants rarely use archives during starting activities. Rather, most participants use these activities to identify and locate archival sources.

Although there were some variations in starting methods among the participants, in general, when they initiate a new project, starting is usually carried out through a combination of searching and communication activities.

Sometimes it is better to start with interviews and sometimes it is better to start with library resources. In any case, the most important thing is to try to go back and forth to different sources. For example, an interview person may reveal a fact that needs to be verified by using other sources (triangulation). When that has been done it may be necessary to go back to the interview person again and rephrase some questions or formulate new in-depth questions regarding a specific topic. (43)

\subsection{Chaining}

Chaining is often used to identify new sources of information or new information needs. It is also used to satisfy potential information needs. Chaining is mainly performed by following references often obtained through reading and personal contacts. All study participants stated that they follow-up references in materials consulted; however, only three participants indicated that they have used Social Science Citation Index (SSCI) for citation searching (12 others used the database for bibliographic searches rather than citation searching). Participants were not asked whether they have access to SSCI, but users indicated mixed feelings about its usefulness:

I haven't found the citation index useful for stuff on [stateless nation]. (3)

Yes. Although I have found this source to be useful, I think it is not as extensive as some of the ones I mentioned earlier. (11)

Yes. A few times, always with the help of a librarian. It has been of modest help to me. (35)

Yes, I have used SSCI. It is fine. Yet, I wish I had the chance to reach the full texts of all the materials I am interested in. (46)
TABLE 8. Criteria used for following-up on citations and/or materials $(n=65)$.

\begin{tabular}{lc}
\hline \multicolumn{1}{c}{ Tool/strategy } & Frequency* \\
\hline Topical relevance & 34 \\
Importance & 13 \\
Author's reputation & 12 \\
Availability (and time it takes to get a hold of the & \\
$\quad$ information/materials) & 11 \\
Curiosity (if item seems interesting) & 9 \\
Novelty (new information) & 8 \\
Publisher's reputation & 8 \\
Utility (usefulness) & 8 \\
Cost & 7 \\
Frequency of citations & 7 \\
Instinct & 5 \\
Nature of citation & 5 \\
Recommendation by colleagues, reviewers, or editors & 5 \\
Date of publication & 3 \\
Location of item & 3 \\
Challenges own ideas & 2 \\
If item is published in a refereed journal & 1 \\
\hline
\end{tabular}

* Figures refer to number of participants indicating each criterion.

Most study participants seem to use the classic approach of chaining as is illustrated by the following two quotations:

I use abstracts and indexes, but my main references seem to come from following a chain of secondary citations and references. (27)

Citations and references in the texts I read have always been quite helpful. (46)

The decision to follow-up on citations is primarily based on topical relevance, importance to one's research, author's reputation and/or identity, novelty, publisher's reputation, cost, frequency of citations, and time it takes to locate the information/materials. Other factors that play into deciding whether to follow-up on a citation include: instinct, nature of citation, and recommendation by colleagues, reviewers, or editors. Table 8 lists all criteria indicated by study participants, and the following quotes present some contextual examples.

Perhaps the author is known to be a good scholar, or the title/subject of the publication is intriguing, or the scope of the work is large enough to demand that I be familiar with it. I am often intrigued by obscure citations of local amateur scholarship, or colonial era publications, because they often contain valuable documentary information which is not dressed-up in the latest or most fashionable academic jargon. (22)

This usually comes down to questions of how long it will take and how much it will cost. Too much (in either or both cases) and I won't bother, unless it appears to be an absolutely vital source. (28) 
It all depends on how crucial I find the information to be. In one case I gave up trying to get information from one government source about election malpractice after fifteen months of telephone calls, personal visits to the concerned government administration, writing letters etc. I soon reached the conclusion that I would not obtain the desired information no matter how hard I tried. But stubbornness pays. After three years of writing letters and calling I finally got my interviews with [person's name]. (43)

As implied in the first two quotations, a significant portion of primary sources (e.g., archival materials and grey literature) is identified during chaining activities.

\subsection{Browsing}

Browsing primary and secondary sources was found to be an important information-seeking activity that all of the study participants had engaged in at some point in their research. Two main types of browsing were identified: (1) the scanning of recently published issues of journals and tables of contents of relevant books; and (2) browsing the online catalog, indexes and abstracts, web resources, and references of materials found and/or read. The following are a few examples of browsing activities as reported by participants:

[I] belong to various discussion lists related to my field, attend conferences every year, browse through social science sections in bookstores as frequently as I can. (9)

I will look at the title of the piece, the author's name and then if all looks promising, the abstract-then order the article on inter-library loan. Otherwise, all is on open access in my university library and so I browse the shelves every quarter for the latest issues. (17)

I find browsing extremely productive, at least as an early step. I then tend to look up citations and references in the literature which I read. I also talk to colleagues a great deal. When I feel I've exhausted all the available existing sources I would then start to carry out original research such as interviews. (28)

[I use] abstracts and indexes; library catalogs; citations of bibliographic references in literature; browsing in stacks remain most important. (30)

On-line browsing is the main means, though I also subscribe to a few journals. (36)

Because of security and safety issues, as well as time and financial constraints, a number of scholars mentioned that they delegate their browsing activities to colleagues, friends, and students.

Whenever I know a colleague or friend is going to Sri Lanka, I usually ask them to browse and pick up certain items for me. (22)
TABLE 9. Methods and tools used to keep up-to-date $(n=65)$.

\begin{tabular}{|c|c|}
\hline Methods/tools & Frequency* \\
\hline Listservs, subscribing to & 24 \\
\hline Journals, subscribing to & 20 \\
\hline Conferences, attending & 18 \\
\hline Colleagues, communicating with & 14 \\
\hline $\begin{array}{l}\text { WWW, browsing, searching for, and monitoring } \\
\text { information published on }\end{array}$ & 14 \\
\hline $\begin{array}{l}\text { Journal articles, books, and grey literature, } \\
\text { reading }\end{array}$ & 13 \\
\hline $\begin{array}{l}\text { Indexes and abstracts, searching and/or } \\
\text { browsing }\end{array}$ & 13 \\
\hline Publishers' catalogs, browsing & 13 \\
\hline Online catalog, searching and/or browsing & 10 \\
\hline Book reviews, monitoring & 8 \\
\hline Journals, browsing table of contents of relevant & 8 \\
\hline $\begin{array}{l}\text { Newspapers, following-up local-primarily on } \\
\text { the web, monitoring }\end{array}$ & 7 \\
\hline $\begin{array}{l}\text { Current awareness tools, subscribing to, } \\
\text { browsing, and monitoring }\end{array}$ & 6 \\
\hline Bookstores, browsing shelves in & 5 \\
\hline $\begin{array}{l}\text { Citations and references in materials used, } \\
\text { reading and following }\end{array}$ & 5 \\
\hline $\begin{array}{l}\text { Book ads in journals, newsletters, etc., } \\
\text { monitoring }\end{array}$ & 3 \\
\hline Graduate students, supervising & 2 \\
\hline Manuscript reviewers, recommendations by & 1 \\
\hline Research assistants, help from & 1 \\
\hline
\end{tabular}

* Figures refer to number of participants indicating each method/tool.

Citations and references in the texts I read have always been quite helpful. Besides, I regularly browse the academic databases available in my university (such as SSCI and EBSCO HOST). Of course, sometimes, though not very often, friends who know my research interests also let me know about some materials. (46)

Whereas delegation of browsing activities may allow for many relevant items to be missed, it is, in some cases, the only way to locate and acquire what might otherwise be inaccessible materials.

\subsection{Monitoring}

Monitoring is characterized by activities involved in maintaining awareness of research developments in one's topic of interest through following, and interaction with, particular sources. Both formal and informal information channels are used for keeping up-to-date, the former by means of listservs, journals, conference proceedings, newspaper articles, book reviews, publishers' ads and catalogs, and Web sources, the latter (i.e., informal channels) by means of personal exchanges with colleagues, friends, and students-by mail, e-mail, and in-person. Table 9 lists all methods and tools that the study participants use to keep up-to-date. Examples of participants' answers to monitoring questions include:

I've come to rely increasingly on listservs of scholars and activists concerned about a particular area; this has made things a lot easier. (47) 
Relevant journals send me their table of contents and I hunt down the articles that I want. I do regular searches through the library's collection of books and journals increasingly via the net. (49)

I subscribe to academic journals, I attend academic conferences, I subscribe to e-mail services that provide table of contents of periodicals I am interested in but do not subscribe to, I attend local seminars of colleagues in my field. I read book reviews. (55)

\subsection{Accessing}

Starting, chaining, browsing, monitoring, extracting, and networking are all fundamental information-seeking activities. For the information-seeking process to continue, however, researchers need to get hold of, or access, the materials or sources of information they identified and located. This is particularly true because starting, chaining, and browsing activities are not all performed with direct sources of information. Rather, a great deal of information is identified through bibliographic databases, personal contacts, recommendations from colleagues, interviews, publisher's catalogs, and backward and forward chaining. That is probably why most study participants have repeatedly brought up the issue of access problems in their responses.

The difficulty is sometimes in the interviewing process (fieldwork) where sometimes, for reasons of security, I was not able to go to the places I had wanted to. (2)

Some published sources are rare. . some are not findable. Some require trips long distances. (21)

[Identity] academic books published in [country] are very hard to get in the US, unlike books from [identity] publishers. (22)

The difficulty is not finding information; it is accessing the information which is difficult. (44)

Apart from using their personal collection and borrowing materials from local university collections and collections of other universities (through personal visits or interlibrary loan requests), study participants often indicated contacting or meeting with the source of information directly (e.g., individuals, government agencies, and ethnic organizations) as well as overseas traveling to the location of the needed material (e.g., archives and foreign national libraries). Because time, funding requirements, and governmental restrictions for accessing some relevant materials are great barriers for many researchers, scholars sometimes resort to alternative sources or methods for obtaining information, often using secondary sources.

It is still very difficult to get into Indian archives without a lot of persuasion, administration and bureaucracy. This is fundamentally a political and financial question that I can- not solve. I usually have to go round this problem by going to colonial archives in London, etc. (33)

As this quote implies, the use of alternative sources of information and persistence in searching for information may depend on factors such as the perceived importance of that information, the urgency with which it is needed, and the perceived severity of the consequences of not having the information.

\subsection{Differentiating}

As in Ellis's studies, differentiating here is characterized through activities undertaken when information sources are evaluated or judged according to their nature, quality, relative importance, and usefulness as a way of filtering the amount and nature of information obtained based on the participants' own perceptions: "Fieldwork [is] of particular importance to my research. This type of data on my topic provides more objective, first-hand data. The other types of data may pose a question of objectivity" (18). One difference between Ellis's findings and those of this study is that differentiating decisions are often based on the identity or origin of the information sources used, which according to the majority of participants, poses considerable concerns regarding "bias."

The reliability of government information is the most problematic issue. Second, in the case of the regional press, accuracy is highly suspect. Hence information has to be checked and cross checked as often as possible. (4)

In the [country] context, a good deal of scholarship has a hidden (or not so hidden) political agenda. I always try to figure out where the author, or the publisher is coming from before I invest lots of energy in a close reading. Sponsors of international conferences are sometimes politically affiliated or financed. Certain newspaper publishers in [country] are known for their political loyalties, so their reports may be slanted, although still useful. Years of experience have given me some ability to spot the signs of political bias, and I am always sensitive to that. (22)

To overcome the problems of bias, participants acknowledged the use of information from different sources:

Information from ethnic organizations is essential to balance official information. (6)

One needs a diversity of sources, not a slew of sources from one country or of one orientation. (29)

Indeed, one common differentiation with those who work on nation states is that the information generated by official sources, usually carries the imprimatur of being more "authentic" and "reliable" than non-state sources. I would tend to take issue with this as a generalization (since government sources can be just as biased and self-serving as any other political actor). (56) 
[Information produced by ethnic organizations] is important only when I am looking into their view of things. Sometimes, their view casts doubt on newspaper accounts of various events and is well worth considering as an interpretive tool or as a corrective to biased news reportage. (60)

Participants also discussed other criteria in differentiating between sources. For example, one participant mentioned that she follows a certain newspaper rather than the other because she can download its articles in seconds, whereas each operation on another newspaper "takes at least 4 minutes, if not 25 , to accomplish" (28).

\subsection{Extracting}

Extracting involves activities associated with going through a particular source or sources and selectively identifying relevant material from those sources. Data collected and analyzed here identified two types of extracting activities: those applied on direct sources (e.g., books and journal articles) and those applied on indirect sources (e.g., bibliographies, indexes and abstracts, and online catalogs).

Since there are few books and articles directly on the Kurds, I have to use other books and articles quite creatively in order to find (hidden) information on the Kurds, e.g., by looking at migrants' region of origin or data organized by region or on the region mainly inhabited by Kurds. (40)

Often the nations in question are not even to be found through many conventional searches; I have to look under Morocco to find information on Western Sahara, Indonesia to find information on East Timor, etc. (47)

Often it is the problem of too much information, and the problem is sorting through to find the most relevant. (48)

\subsection{Verifying}

Verifying is characterized by activities associated with checking the accuracy of the information found. The study participants emphasized these activities primarily because of the political and sensitive nature of their research topics. Many participants wrote about "bias," "disinformation," and lack of "reliability" and "accuracy" of many sources of information they encounter, especially among materials produced by ethnic and governmental organizations as well as those published on the Web.

First, the reliability of government information is the most problematic issue. Second, in the case of the regional press, accuracy is highly suspect. Hence information has to be checked and cross-checked as often as possible. (4)

Some material is available on the Internet which is difficult to verify or counter, so it is not always easy to evaluate some possible sources. (20)
I also often find great information on the internet with no way of verifying its legitimacy or its source. (31)

Participants indicated that they verify the information they collect by asking colleagues, government officials, and members of stateless nations, as well as by gathering information and data from different sources and comparing their own findings with those of others.

\subsection{Networking}

Networking is characterized by activities associated with communicating, and maintaining a close relationship, with a broad range of people such as friends, colleagues, and intellectuals working on similar topics, members of ethnic organizations, government officials, and booksellers. Many participants create, or participate in, networks not only to build collections or gather information, but also to share information with members of these networks: "I send members of this network anything I come across and bother them to send me stuff when I need it (56). According to most participants, the Internet has significantly encouraged their involvement in, and development of, networks. Further discussion on networking is provided in the next section.

\subsection{Information Managing}

Participants in this study repeatedly talked about the need and importance of filing, archiving, and organizing the information they collect or use in facilitating their research.

When it comes to Turkish language sources, I find that I have to search for books and articles during trips to Turkey since they are unavailable in the US. Moreover, I carefully monitor the press (numerous Turkish language papers on the internet) on a daily basis and make systematic efforts at building an archival system composed of as many diverse sources as possible. (4)

I subscribe to journals and professional bodies (MESA, BRISMES, Middle East, amongst others). This is expensive, I also have to store and file the journals. (27)

I have three private archives: 1 . I have a big "conflictarchive" of almost all the publications by the Tamil armed movements and of newspaper articles on the other side. About 50 archival boxes. 2. I have an archive of academic off-prints related to my subject. I am today at box 111. Each box has about 20 articles, that are all registered by me in my homemade database. I can look for subjects, titles, authors. All articles are specialized on my small field of research. 3 . To this comes a gigantic archive with correspondence with colleagues from 1968 onwards. This archive has almost stopped growing since e-mail took over. My e-mail box keeps order now. All these boxes take two rooms in the cellar of my house. I could not work without this private archive. To this comes my private library of books, which takes another room in the cellar. (33) 
Mainly what I do to tell you the truth, I keep sort of journals when I read things and when I have thoughts I have like over the last 15-20 years I have about 20 of these [journals] and when I do fieldwork I keep them with [me] and write everything down and when I read something I write notes down. So in the end, I have an archive that I can refer back to whenever needed. (64)

As can be learned from these quotations, knowledge is not always immediately obtained or applied. It needs to be gathered, digested, organized, and stored for future use. According to the study participants, personal collections not only provide them with easily accessible materials, but also with materials that are organized or classified in a way they understand. Hence, it was not surprising to find that personal collections are one of the most important sources of information for the scholars.

\section{Conclusion}

\subsection{New Features}

This study confirmed Ellis's model. The study, however, found that a fuller description of the information-seeking process of social scientists studying stateless nations should include four additional features besides those identified by Ellis. These new features are: accessing, networking, verifying, and information managing. Although not all of these new features are information searching or gathering activities, they are tasks that have significant roles in enhancing information retrieval and facilitating research.

Many of the study participants reported access problems as barriers to using information (e.g., unavailability of desired publications at own university library and denial of access to information and to the field by governments). These participants indicated that because of these problems, they are required to seek and use other types of materials (e.g., secondary sources), locate and visit different places where relevant information might be found (e.g., major research libraries and own national libraries), and/or travel overseas to the location of needed materials (e.g., foreign archives and national libraries). These and other activities (e.g., borrowing and photocopying material from other libraries, subscribing to relevant publications and listservs, and contacting the source of information directly) suggest that the behaviors associated with the attempts to access the needed information, located through "starting," "chaining," "browsing," "monitoring," and "networking" are major information-seeking activities and therefore should be added to David Ellis's information-seeking model as a distinct category. This is because searching activities (i.e., starting, chaining, browsing, monitoring, differentiating, extracting, and networking) do not necessarily always start with, or lead to, raw materials or direct sources of information. There can be many instances where researchers cannot instantly know whether they will obtain certain materials (e.g., through interlibrary loan or through personal contacts with government officials), be given permission to go to the field to interview or observe people, get enough support (e.g., research grants) to conduct certain activities related to a project, or have enough time to wait for the arrival of relevant materials.

The issue of access problems-brought up by the majority of study participants-provides several potential areas of investigation. First, whereas the access problem is huge for scholars studying stateless nations, it can also be significant for other groups of social scientists, especially those involved in interdisciplinary research or in understudied research topics. For example, Westbrook (1997, 1999) discusses information access issues for women's studies scholars, and concludes that the information barriers faced by faculty in interdisciplinary programs are still being identified and are not yet fully developed. The problem with earlier research, however, is that in most previous studies, researchers tended to focus on: (1) Scholars located in major research universities where access to information is virtually not an issue [Ellis's population and that of Westbrook are good examples of such studies] or (2) Scholars based on their departmental affiliations rather than their research topics (e.g., Bates, 1996; Caidi, 2001). Second, given the importance of archival materials and other forms of primary sources among the study participants, both librarians and archivists need to investigate what happens to research and scholarship when access to information is denied. In the wake of the September 11 attacks and with the fact that most of the FOIA's requests are being automatically denied today, this question seems to be very important for all scholars in the U.S., and not only social scientists studying stateless nations and other similar research topics.

Moreover, participants in this study have stressed the significance of, and need for, creating and maintaining what might be considered international invisible colleges or networks that aim at developing and maintaining a close relationship with a broad range of people such as friends, colleagues, scholars working on similar topics, members of ethnic organizations, government officials, and booksellers. This is done to build collections, access materials, and gather information, as well as to share information with members of these networks, which are generally open to anyone from graduate students and faculty members to independent scholars, and so on (see Cronin, 1982). The easy access that the Internet allows to, and between, individuals and groups all over the world plays a significant role in further enhancing the importance of networking for research purposes among academic social scientists (Jirojwong \& Wallin, 2002). Whether networking is more critical for scholars studying stateless nations than it is for other scholars cannot be discerned from this study. Therefore, it is important to further investigate the role and importance of networking in, and for, research among this particular group and to find out how networking could be facilitated.

Verifying was identified as a distinct category in Ellis's study, but among physical scientists and engineers rather than social scientists (Ellis, Cox, \& Hall, 1993; Ellis \& 


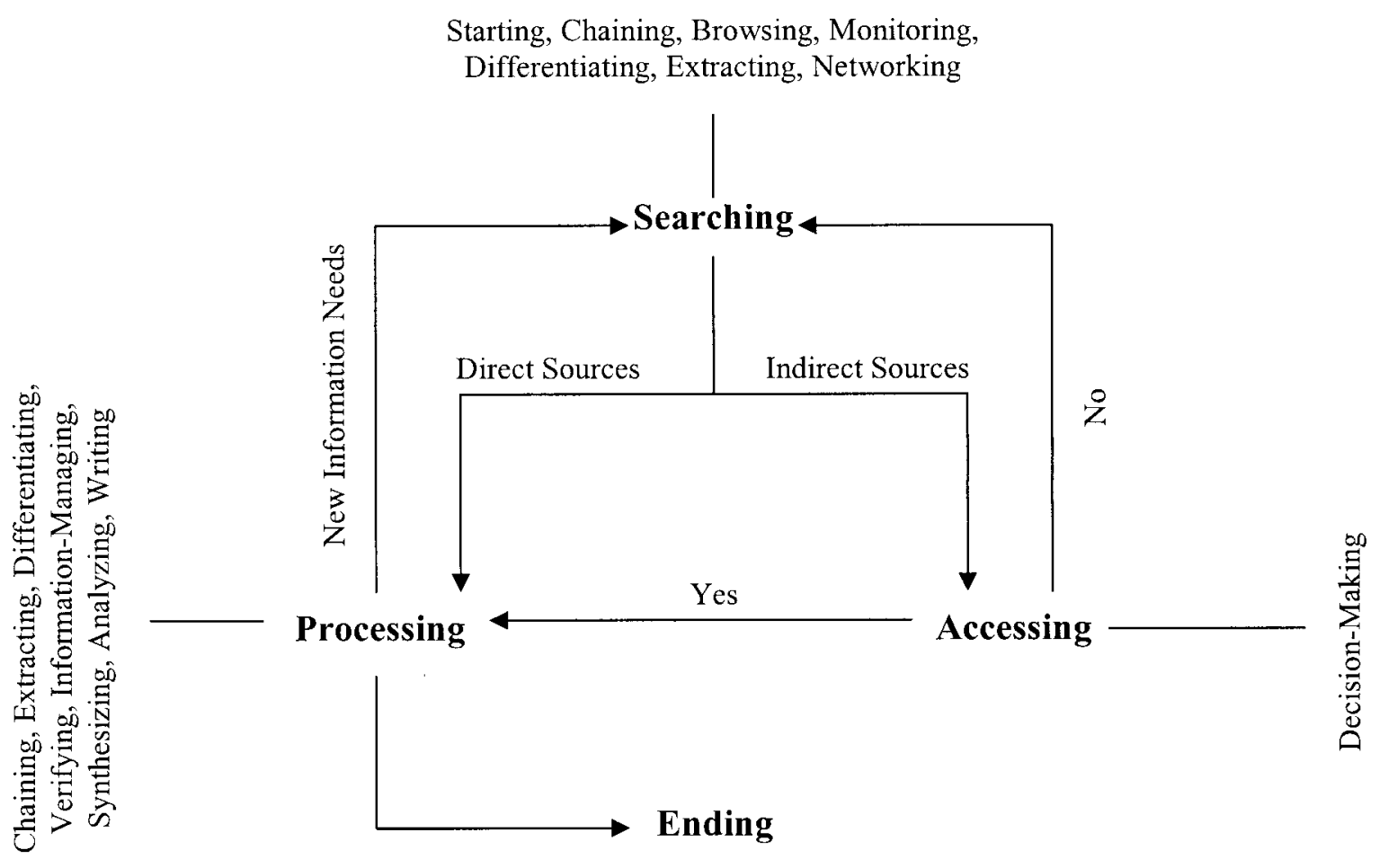

FIG. 1. Stages in the information-seeking behavior of academic social scientists.

Haugan, 1997). Physical scientists, such as chemists, employ verifying activities to authenticate or confirm figures and formulas. In this study, however, participants emphasized verifying activities as part of their information-seeking process because of the "biased" nature of a major proportion of information they locate and use (e.g., information by governments oppressing stateless nations, as well as information by ethnic organizations). Another reason why verifying activities were emphasized here is because of the use of web resources, which, according to most participants, lack accuracy, reliability, and authenticity. The use of web resources did not apply to participants in Ellis's study as his study on social scientists was conducted before the existence of the web.

The number of published studies specifically on faculty acceptance and use of web sources for research is still small. Among these studies, however, several have focused on the issue of value, quality, and authority of web sources (e.g., Bruce \& Leander, 1997; Cronin \& McKim, 1996), as well as on faculty satisfaction with such sources (e.g., Herring, 2001). Having identified several differences between social scientists studied here and the universal population of academic social scientists (e.g., in terms of use of archival materials as well as heavy reliance on personal collection, fieldwork data, grey literature, and access), it may very well be the case that different groups of social scientists may evaluate and use web resources differently.

Information managing is yet another information-seeking activity that was not identified as a category in Ellis's study of social scientists, even though its importance and influence on accessing and on information seeking behavior in general was discussed by a number of earlier studies (e.g., Soper, 1976; Case, 1986, 1991; Nair, 1989). Participants in this study repeatedly talked about filing, archiving, and organizing the information they collect or use. Although these processes are the exact opposite of information searching or gathering activities, they are activities that have a significant role in enhancing information retrieval, especially in cases where personal collection is of utmost importance (Soper, 1976).

\subsection{New Model}

Similar to what Ellis found, the activities identified in this study-starting, chaining, browsing, differentiating, monitoring, extracting, accessing, networking, verifying, and information managing - are not necessarily entirely or always sequential. Scholars move from one research activity to another based on their momentary or changing needs. In general, however, the information-seeking activities of academic social scientists-based on the group of scholars studied here-can be divided into four interrelated stages: searching, accessing, processing, and ending (see Fig. 1).

The searching stage can be defined as the period where identifying relevant and potentially relevant materials is initiated. It includes both information-gathering activities using traditional tools (e.g., online catalogs and indexes and abstracts) as well as communication with people and other sources of information (e.g., publishers, booksellers, and government agencies). The accessing stage can be defined as the bridge between the searching stage and the processing 
stage, especially when indirect sources of information are used (e.g., online catalogs, indexes and abstracts, and bibliographies). The processing stage is where the synthesizing and analyzing of the information gathered takes place. Also taking place in the processing stage is the writing of the final product. The ending stage marks the end of the research cycle of a project. Although it was not discussed in this study, an ending stage was assumed as all interview questions were geared toward discussing the entire research cycle of a project (e.g., "When you write a book or a paper for a journal, where and how do you start looking for information?").

As shown in Figure 1, in each of the first three stages (i.e., searching, accessing, and processing), a number of activities could take place. During the searching stage, researchers might use starting, chaining, browsing, monitoring, differentiating, extracting, and networking activities. During the accessing stage, researchers become involved in decision-making activities with regard to proceeding to the processing stage or returning to the searching stage. This decision is based on the success or failure of obtaining needed materials and/or gaining access to various sources and types of information (e.g., subjects, archival materials, and government documents). During the processing stage, researchers might use chaining, extracting, differentiating, verifying, and information-managing activities. During the processing stage too, researchers engage in synthesizing and analyzing the information they gathered and in writing their final products.

Figure 1 also shows that once the research cycle starts at the searching stage, researchers may continue to the accessing stage or to the processing stage, or to both, depending on the initial types of information used: indirect or non-fulltext sources and direct or full-text sources (e.g., books and journal articles). In case only the latter sources are used, a researcher may skip the accessing stage and go directly to the processing stage. However, in case indirect sources are utilized, the accessing stage becomes necessary because without having the full text of items identified in the searching stage, researchers may not want, or be able, to proceed to the processing stage. This is especially so when the sources in question are of utmost importance to the research. Therefore, access to direct sources is, in some cases, indispensable for the research cycle to continue. In case both direct and indirect sources were used in the searching stage, a researcher may proceed to both accessing and processing stages.

Moreover, as was found in this study, when access to relevant or potentially relevant information or sources of information is not possible, researchers try to use alternative sources or methods. This could be searching for new information (i.e., returning from the accessing stage to the searching stage) or continue working with whatever information has been obtained-that is, moving from the accessing stage to the processing stage even though some potentially relevant items were not accessed. In the latter case, researchers may rely on secondary sources or on informa- tion they could obtain. Also found in this study is the fact that during the processing stage new questions may arise or new information needs may develop, which may require the scholars to return to the searching stage.

In general, researchers move back and forth between the searching, accessing and/or the processing stages until the project is completed (ending stage). ${ }^{8}$

\section{Implications}

Although much has been learned about the informationseeking behavior of social science faculty, there is still a need for more studies to verify the results reported here. Of particular importance would be examining groups of scholars that conduct research on non-citizen groups and/or ethnic and religious minorities in the United States and Europe. These studies should consider the triangulation of research methods for data collection, particularly surveys and interviews (both face-to-face and telephone and/or computermediated). Each of the new information-seeking behavior features identified in this study-accessing, networking, verifying, and information managing-call for some enhancements in the design of existing information systems and services. Part of the accessing problems presented here (e.g., lack of resources in own university libraries and use of non-digitized archival materials) could be addressed by more collaboration and networking among libraries as well as by the various digital library projects and increased access to databases with full-text items. Networked electronic access to unique archival materials stands as a very attractive information access strategy for research communities such as the group of scholars discussed here who are dispersed around the globe. Authentication of digital data, a key issue within archival world today, looms even larger for

\footnotetext{
${ }^{8}$ The following is a sample of quotations from study participants describing their initial research activities:

- Extensive reading, checking bibliographies of scholarly journals and checking information that I receive over my relevant e-mail lists. I also depend on other scholars who are also friends who provide me with new sources. (26)

- I find browsing extremely productive, at least as an early step. I then tend to look up citations and references in the literature, which I read. I also talk to colleagues a great deal. When I feel I've exhausted all the available existing sources I would then start to carry out original research such as interviews. (28)

- Naturally I use searches at libraries and searches from my computer, via for example SSCI, to find relevant articles on a topic. These articles may suggest useful sources to look closer at when an investigation is to be started. But after that, one has to rely more on information from interviews. Interviews create snowball effectsi.e., one interview may provide information that tells you about two or three other persons that should be interviewed, and so on. (43)

- Search on Internet and databases for literature on existing sub-topics, order the books and articles from university or other libraries. If I find something relevant, I look at the reference and then see if anything interests me from here. The lead on provided by each work is quite important. Write to organizations dealing with particular issues and ask specific and general questions. Give them an idea of my work and ask if they can suggest someone who might be of some help or some existing literature that I might have overlooked. (50)
} 
researchers of stateless nations due to sensitive political considerations.

Both networking and verifying could be facilitated by including the corporate source field and full contact information of authors in both indexing and abstracting services and in online catalogs. Including journal type field in periodical databases (e.g., academic, professional, refereed, non-refereed, governmental, and so on) could also facilitate verifying and so does a filtering system that could eliminate those Web pages that do not have author names and/or author affiliations and contact information. The Internet has added a new dimension to the information-seeking behavior of scholars in that some of the needed information, if and when found, has a high chance of appearing as a full-text. The problem, however, is that only a small fraction of available information is digitized and made accessible to researchers.

Finally, certain research subjects, such as stateless nations, must be indexed under their proper names rather than obscure terms. This will not only enhance information retrieval, but it will also facilitate classification and collection organization. Scholars may have ways of managing the information they gather that may be different and/or better than those of information centers and systems serving them. Future studies should investigate such differences and examine the relationships. Future studies should also investigate which other groups of academic social scientists differ from the mainstream, universal population of such scholars, in terms of their information-seeking behavior and information environment.

\section{References}

Alberani, V., Pietrangeli, P.D.C., \& Mazza, A.M.R. (1990). The use of grey literature in health sciences: A preliminary survey. Bulletin of the Medical Library Association, 78(4), 358-363.

American Psychological Association (1963-1969). Reports of the project on specific information exchange in psychology, 3 vols. Washington, DC: American Psychological Association.

Bates, M.J. (1989). The design of browsing and berrypicking techniques for the online search interface. Online Review, 13(5), 407-424.

Bates, M.J. (1996). Learning about the information seeking of interdisciplinary scholars and students. Library Trends, 45(2), 155-164.

Bath University (1979). The structure of social science literature as shown by citations. Bath: Bath University. [Design of information systems in the social sciences. Research reports, Series A; 3.]

Bath University (1980). Towards the improvement of social science information systems: Overview of research carried out 1971-1975. Bath: Bath University. [Design of information systems in the social sciences. Research reports, Series A; no. 1.]

Belkin, N.J., Oddy, R.N., \& Brooks, H.M. (1982a). ASK for information retrieval: Part 1. Background and theory. Journal of Documentation, 38(2), 61-71.

Belkin, N.J., Oddy, R.N., \& Brooks, H.M. (1982b). ASK for information retrieval: Part 2. Results of a design study. Journal of Documentation, 38(3), 145-164.

Bozarslan, H. (2000). Research guide: Kurdish studies. Available: http:// www.biu.ac.il/SOC/besa/ meria/research-g/kurds.html (accessed November 13,2001$)$.

Broadus, R.N. (1977a). Evaluation of academic library collections: A survey of recent literature. Library Acquisitions: Practice and Theory, 1(3), 149-155
Broadus, R.N. (1977b). The applications of citation analyses to library collection building. In M.J. Voigt \& M.H. Harris (Eds.), Advances in librarianship, vol. 7 (pp. 299-335). New York: Academic Press.

Broadus, R.N. (1980). Use studies of library collections. Library Resources \& Technical Services, 24(4), 317-324.

Bruce, B.C., \& Leander, K.M. (1997). Searching for digital libraries in education: Why computers cannot tell the story. Library Trends, 45(4), $746-770$.

Buttlar, L., \& Wynar, L.R. (1992). Cultural pluralism and ethnic diversity: Authors as information users in the field of ethnic studies. Collection Management, 16(3), 13-33.

Caidi, N. (2001). Interdisciplinarity: What is it and what are its implications for information seeking? Humanities Collections, 1(4), 35-46.

Carroll, B.C., \& Cotter, G.A. (1997). A new generation of grey literature: The impact of advanced information technologies. Publishing Research Quarterly, 13(2), 5-14.

Case, D.O. (1986). Collection and organization of written information by social scientists and humanists: A review and exploratory study. Journal of Information Science, 12(3), 97-104.

Case, D.O. (1991). The collection and use of information by some American historians: A study of motives and methods. The Library Quarterly, $61,61-82$.

Choo, C.W., Detlor, B., \& Turnbull, D. (1998). A behavioral model of information seeking on the Web: Preliminary results of a study of how managers and IT specialists use the Web. Proceedings of the ASIS Annual Meeting, vol. 35 (pp. 290-302). Medford, NJ: Information Today

Choo, C.W., Detlor, B., \& Turnbull, D. (2000). Information seeking on the Web: An integrated model of browsing and searching. Available: http:// firstmonday.org/issues/issue5_2/choo/index.html (last visited June 2, 2002).

Christiansen, D.E., Davis, C.R., \& Reedscott, J. (1983). Guide to collection evaluation through use and user studies. Library Resources \& Technical Services, 27(4), 432-440.

Ciment, J. (Ed.) (1999). Encyclopedia of conflicts since World War II, 4 vols. Armonk, NY: Sharpe Reference.

Cronin, B. (1982). Invisible colleges and information transfer: A review and commentary with particular reference to the social sciences. Journal of Documentation, 38(3), 212-236.

Cronin, B., \& McKim, G.W. (1996). Science and scholarship on the world wide web: A North American perspective. Journal of Documentation, 52(2), 163-171.

Curasi, C.F. (2001). A critical exploration of face-to-face interviewing vs. computer-mediated interviewing. International Journal of Market Research, 43(4), 361-375.

Dervin, B., \& Nilan, M. (1986). Information needs and uses. In M.E. Williams (Ed.), Annual review of information science and technology, vol. 21 (pp. 3-33). White Plains, NY: Knowledge Industry Publications.

Earle, P., \& Vickery, B.C. (1969). Social science literature use in the U.K. as indicated by citations. Journal of Documentation, 25(2), 123-141.

Ellis, D. (1987). The derivation of a behavioural model for information retrieval system. Unpublished doctoral dissertation, University of Sheffield, United Kingdom.

Ellis, D. (1989). A behavioral approach to information retrieval system design. Journal of Documentation, 45(2), 171-212.

Ellis, D. (1993). Modeling the information-seeking patterns of academic researchers: A grounded theory approach. The Library Quarterly, 63(4), $469-486$.

Ellis, D., Cox, D., \& Hall, K. (1993). A comparison of the information seeking patterns of researchers in the physical and social sciences. Journal of Documentation, 49(4), 356-369.

Ellis, D., \& Haugan, M. (1997). Modelling the information seeking patterns of engineers and research scientists in an industrial environment. Journal of Documentation, 53(4), 384-403.

Farace, D.J. (2000). New frontiers in grey literature: Fourth International Conference on Grey Literature, Kellogg Conference Center, Washington, D.C., October 4-5, 1999; GL'99 Proceedings, GreyNet, Amsterdam, The Netherlands. 
Fidel, R. (1993). Qualitative methods in information retrieval research. Library \& Information Science Research, 15(3), 219-247.

Garvey, W.D., \& Griffith, B.C. (1963). An overview of the structure, objectives, and findings of the American Psychological Association's project on scientific information exchange in psychology. Washington, DC: American Psychological Association.

Garvey, W.D., \& Griffith, B.C. (1964). Scientific information exchange in psychology. Science, 146(3652), 1655-1659.

Garvey, W.D., \& Griffith, B.C. (1965). Scientific communication: The dissemination system in psychology and a theoretical framework for planning innovations. American Psychologist, 20(2), 157-164.

Garvey, W.D., \& Griffith, B.C. (1966). Studies of social innovations in scientific communication in psychology. American Psychologist, 21(11), 1019-1036.

Garvey, W.D., \& Griffith, B.C. (1967). Scientific communication as a social system. Science, 157(3792), 1011-1015.

Garvey, W.D., \& Griffith, B.C. (1971). Scientific communication: Its role in the conduct of research and creation of knowledge. American Psychologist, 26(4), 349-362.

Garvey, W.D., Lin, N., \& Nelson, C.E. (1970). Communication in the physical and the social sciences. Science, 170(3963), 1166-1173.

Garvey, W.D., Lin, N., \& Nelson, C.E. (1971). Scientific communication behavior of social and physical scientists. International Social Science Journal, 23(3), 256-271.

Gelfand, J.M. (1997). Academic libraries and collection development implications for grey literature. Publishing Research Quarterly, 13(2), $15-23$.

Gurr, T.R. (2000). Peoples versus states: Minorities at risk in the new century. Washington, DC: United States Institute of Peace Press.

Hernon, P. (1984). Information needs and gathering patterns of academic social scientists, with special emphasis given to historians and their use of united states government publications. Government Information Quarterly, 1(4), 401-429.

Herring, S.D. (2001). Using the world wide web for research: Are faculty satisfied. The Journal of Academic Librarianship, 27(3), 213-219.

Hobohm, H.-C. (1999). Social science information and documentation: Time for a state of the art? Inspel, 33(3), 123-130.

Institute for Scientific Information (2002). Social Sciences Citation Index. Philadelphia: Institute for Scientific Information [electronic database].

Jirojwong, S., \& Wallin, M. (2002). Use of formal and informal methods to gain information among faculty at an Australian regional university. The Journal of Academic Librarianship, 28(1-2), 68-73.

Kelly, G. (1963). A theory of personality: The psychology of personal constructs. New York: Norton.

Kuhlthau, C.C. (1988). Developing a model of the library search process: Cognitive and affective aspects. RQ, 28(2), 232-242.

Kuhlthau, C.C. (1991). Inside the search process: Information-seeking from the user's perspective. Journal of the American Society for Information Science, 42(5), 361-371.

Kuhlthau, C.C. (1993). Seeking meaning: A process approach to library and information services. Norwood, NJ: Ablex.

Library: University of California at Berkeley (2002). Library research using primary sources. Available: http://www.lib.berkeley.edu/TeachingLib/Guides/PrimarySources.html

Line, M.B. (1971). The information uses and needs of social scientists: An overview of INFROSS. Aslib Proceedings, 23(8), 412-434.

Line, M.B. (1973). Information needs of the social sciences. INSPEL, 8(2), 29-39.

Line, M.B. (2000). Social science information: The poor relation. IFLA Journal, 26(3), 177-179.
Line, M.B., Brittain, J.M, \& Cranmer, F.A. (1971). Information requirements of researchers in the social sciences, 2 vols. Bath, England: Bath University of Technology (Library). [Investigation into information requirements of the social sciences, research report, no. 1.]

Marchionini, G. (1995). Information seeking in electronic environments. New York: Cambridge University Press.

McBride, R.B. (1981). Foreign language serial use by social science faculty: A survey. The Serials Librarian, 5(4), 25-32.

Meho, L.I. (2001). The information-seeking behavior of social science faculty studying stateless nations. Unpublished doctoral dissertation, University of North Carolina at Chapel Hill.

Meho, L.I., \& Haas, S.W. (2001). Information-seeking behavior and use of social science faculty studying stateless nations: A case study. Library \& Information Science Research, 23(1), 5-25.

Miles, M.B., \& Huberman, A.M. (1984). Qualitative data analysis: A sourcebook of new methods. Beverly Hills, CA: Sage Publications.

Minahan, J. (1996). Nations without states: A historical dictionary of contemporary national movements. Westport, CT: Greenwood Press.

Murray, P.J. (1995). Research from cyberspace: Interviewing nurses by e-mail. Health Informatics, 1(2), 73-76.

Murray, P.J. (1996). Nurses' computer-mediated communications on NURSENET: A case study. Computers in Nursing, 14(4), 227-234.

Murray, C.D., \& Sixsmith, J. (1998). E-mail: A qualitative research medium for interviewing? International Journal of Social Research Methodology, 1(2), 103-121.

Nair, M.C. (1989). Social science information, users, and research libraries: Significance of organization of information. IASLIC Bulletin, 34(3), $129-136$.

Neuendorf, K.A. (2002). The content analysis guidebook. Thousand Oaks, CA: Sage Publications.

Pettigrew, K.E., Fidel, R., \& Bruce, H. (2001). Conceptual frameworks in information behavior. Annual Review of Information Science and Technology, 35, 43-78.

Roberts, C.W. (Ed.) (1997). Text analysis for the social sciences: Methods for drawing statistical inferences from texts and transcripts. Mahwah, NJ: Erlbaum.

Soper, M.E. (1976). Characteristics and use of personal collections. The Library Quarterly, 46(4), 397-415.

Stenstrom, P., \& McBride, R.B. (1979). Serial use by social science faculty: A survey. College \& Research Libraries, 40(5), 426-431.

Subrahmanyam, T. (1983). A study of information-seeking behaviour of doctoral candidates in social sciences. Herald of Library Science, 22(3), 200-204.

Sutton, S.A. (1994). The role of attorney mental models of law in case relevance determinations: An exploratory analysis. Journal of the American Society for Information Science, 45(3), 186-200.

Vijayakumar, K.P. (1997). Information sources and services in social sciences. Kelpro Bulletin, 1(1), 15-26.

Wang, P. (1999). Methodologies and methods for user behavioral research. Annual Review of Information Science and Technology, 34, 53-99.

West, M.D. (Ed.) (2001). Theory, method, and practice in computer content analysis. Westport, CT: Ablex.

Westbrook, L. (1997). Information access issues for interdisciplinary scholars: Results of a Delphi study on women's studies research. Journal of Academic Librarianship, 23(3), 211-216.

Westbrook, L. (1999). Interdisciplinary information seeking in women's studies. Jefferson, NC: McFarland \& Co.

Wilson, T.D. (1999). Models in information behavior research. Journal of Documentation, 55(2), 249-270. 